\title{
Vulvovaginal Candidiasis Symptom Reduction - Honey, Yogurt-and-Honey and Clotrimazole Vaginal Cream - A Triple Blind Randomized Control Trial
}

\author{
Fereshteh Jahdi ${ }^{1}$, Zeinab Hamzehgardeshi², Maryam Darvishi Kuolaei ${ }^{3}$, Mohsen Vahedi ${ }^{4}$, Saied Goodarzi ${ }^{5}$ \\ ${ }^{1}$ Department of Nursing and Midwifery, Nursing Care Research Centre, Iran University of Medical Sciences, \\ Tehran, Iran. ${ }^{2}$ Sexual and Reproductive Health Research Center, Department of Reproductive Health \\ and Midwifery, School of Nursing and Midwifery, Mazandaran University of Medical Sciences, Sari, \\ Iran. ${ }^{3}$ Department of Nursing and Midwifery, Tehran University of Medical Sciences, Tehran, Iran. \\ ${ }^{4}$ Department of Biostatistics, University of Social welfare and Rehabilitation Sciences, Tehran, \\ Iran. ${ }^{5}$ Department of Pharmacy, Tehran University of Medical Sciences, Tehran, Iran.
}

\section{ABSTRACT}

\section{BACKGROUND}

Candida vulvovaginitis is one of the most common infections of the female at reproductive age that affects the quality of their life. Antifungal effects of honey, yogurt and the tendency of using herbs has encouraged us to conduct this study. This study was done to determine the effects of yogurt \& honey and honey vaginal cream on the symptoms of vaginitis.

\section{METHODS}

In this randomized, triple blind clinical trial of 105 non-pregnant women with candida vulvovaginitis were placed in three groups of vaginal cream, mixture of yogurt and honey recipients $(\mathrm{N}=35)$, honey vaginal cream $(\mathrm{N}=35)$ recepients and clotrimazole vaginal cream $(\mathrm{N}=35)$ recipients. Each group was treated for 7 days. At the beginning of study, clinical and laboratory signs and symptoms were registered 7 and 14 days after treatment by questionnaire, observation forms and culture results of secretions. Data by chi-square test, analysis of variance (ANOVA), McNemar's tests were analysed by Statistical Package for the Social Sciences (SPSS) version 21. Significance level of 0.05 was considered.

\section{RESULTS}

There are significant differences in symptom improvement of "yogurt and honey", "honey" than "clotrimazole group" ( $p<0.05)$ and also positive results of the first cultures (one week after treatment) in "yogurt and honey", "honey" and "clotrimazole" (31 / 4\%, 37 / $1 \%$ versus $20 \%$ ) and second time cultivation (14 days after treatment) (28 / $6 \%, 31 / 4 \%$ versus $14 / 3 \%)$ were similar and there were no significant differences between the two groups. $(\mathrm{P}>0.05)$.

\section{CONCLUSIONS}

Therapeutic effects of honey, and yogurt-and-honey are not only similar to that of clotrimazole vaginal cream, but are more effective in relieving some symptoms of vaginal candidiasis. Therefore, use of this product can be suggested as a herbal remedy for candida infection treatment.

\section{KEY WORDS}

Vulvovaginal Candidiasis, Honey, Yogurt, Clotrimazole
Corresponding Author: Maryam Darvishi Kuolaei, School of Nursing and Midwifery, Tehran University of Medical Science, Tehran, Iran.

E-mail:sepide_d77@yahoo.com

DOI: $10.14260 / j e m d s / 2021 / 112$

How to Cite This Article:

Jahdi F, Hamzehgardeshi Z, Kuolaei MD, et al. Vulvovaginal candidiasis symptom reduction - honey, yogurt-and-honey and clotrimazole vaginal cream - a triple blind randomized control trial. J Evolution Med Dent Sci 2021;10(08):515-521, DOI: $10.14260 / j e m d s / 2021 / 112$

Submission 23-09-2020,

Peer Review 17-11-2020,

Acceptance 23-11-2020,

Published 22-02-2021.

Copyright (c) 2021 Fereshteh Jahdi et al. This is an open access article distributed under Creative Commons Attribution License [Attribution 4.0 International (CC BY 4.0)] 


\section{BACKGROUND}

Candida vulvovaginitis is infection in genital organ by candida agent and according to statistics, it is the second reason for occurrence of vaginal infection.1-5 The reports suggest that among every four females, three suffer from such infection. ${ }^{6}$ Among them, 10 million females were referred annually to specialists in clinical centres. ${ }^{7}$ The important point is that high load of diseases led to imposing 1.8 US dollars (USD) to medical costs. On the other hand, it is predicted by 2030, number of females, who suffer from candida vulvovaginitis , to increase about 158 million subjects. ${ }^{8}$ It is noteworthy in Iran $47.4 \%$ of females suffer from this disease. ${ }^{9}$ Similarly, it is estimated $70-75 \%$ of females to suffer from candida vulvovaginitis at least once in their lifetime where $40-50 \%$ of females are subject to recurrence of candida vulvovaginitis .10 More than $90 \%$ of vaginal candida infections are caused by Candida albicans and there are only $10 \%$ of cases of other varieties e.g. glabrata, krusei and parapsilosis. ${ }^{11}$

Although candida vulvovaginitis is not a threatening disease for life, it can cause physical, mental and sexual side effects. Therefore, it is assumed as a serious challenge for public health. ${ }^{4,10}$

The risk of this infection include patients with defective immunity system, pregnant females, diabetic patients, females who take oral contraceptive pills with high estrogenic, patients with acquired immunodeficiency syndrome (AIDS) and patients under antibiotic therapy.7,12,13 The symptoms of candida vulvovaginitis include vaginal secretion, dysuria, itching, painful and burning urination, swelling, dyspareunia and general uneasiness. ${ }^{14-17}$ Thus, candida vulvovaginitis is more diagnosed based on history of disease because due to disability of normal techniques, genital examination is difficult to identify specific organism. ${ }^{18}$ Therefore, azole drugs are taken as the first therapeutic line systematically and or topically to treat clinical symptoms. The important point is that some females may suffer from side effects of such drugs. ${ }^{4}$ Failure of effective treatments and medicinal resistance against azoles and their side-effects led to a tendency to discovery of new antifungal drugs with lesser side effects. ${ }^{19,20}$ Honey is one of the antifungal drugs that has been used as drug because of antimicrobial and antibacterial effects since several millennia ago, but due to lack of scientific support in modern medicine it was used with limitation. ${ }^{21,22}$

The antimicrobial activity of honey is due to hydrogen peroxide derived from glucose and oxygen by glucose oxidase enzyme at first place. ${ }^{23}$ Several studies have reported that honey, as a dressing, is very effective in treating wounds, burns, dermal wounds and inflammation.24,25 For example, results of study done by Estrome et al. showed that if probiotic vaginal capsule, including lactobacillus, is taken directly in vagina of females, who suffered from Candida vulvovaginitis , for 5 days, it could treat this infection at level of $93 \%$ against quantity of $83 \%$ placebo. Given the above said study, it is inferred that the existing lactobacillus in yogurt may inhibit growth of fungus in vagina of females with Candida vulvovaginitis by creating acid medium as well as producing metabolites e.g., hydrogen peroxide. ${ }^{26}$
Likewise, in study of El-Willy et al. using honey in culture medium with candida vulvovaginitis for 2 - 6 hours it inhibited growth in candida vulvovaginitis ,27 Reda et al. also indicated significant statistical reduction in treatment of candida vulvovaginitis in females, who consumed sidr honey in their study. ${ }^{28}$ However, there was no significant statistical difference among consuming yogurt with acidophilus and pasteurized yogurt for inhibition from recurred in study done by Shalev et al. (1996) ${ }^{29}$

Due to the lack of studies on the effect of yogurt on candidiasis vaginitis and inconsistencies in studies, the present research aims to do controlled clinical trial to compare impact of vaginal honey cream, yogurt-honey mixture with clotrimazole in treatment of symptoms of candida vulvovaginitis.

\section{METHODS}

\section{Trial Design}

The present research is a random triple blind clinical trial with control group under REG No 14201401052248 that was conducted to compare effect of honey vaginal cream alone and in combination with yogurt and clotrimazole on symptoms of candida vulvovaginitis in referent females to clinical and healthcare centres of Mazandaran University of Medical Sciences in Sari city within years (December 2013 - May 2014).

\section{Participants}

The study inclusion criteria comprised of females of age range (18 - 45), with existing symptoms of candida vulvovaginitis in interview \& observation and confirmation of the same by laboratory tests, absence of pregnancy, with no history for taking antifungal and wide-range antibiotic drugs and corticosteroids during two recent weeks, absence of allergy to honey and patients not suffering from diabetes. The exclusion criteria consisted of pregnancy, menstruation and abnormal urethral haemorrhage during treatment. The researcher referred to Imam Khomeini Hospital Complex and medical centres No 5 and 7 in Sari city for data collection after receiving permission from ethics committee of Tehran and Mazandaran Universities of Medical Sciences.

\section{Interventions}

The researcher after receiving permission from the Ethics Committee of the University of Medical Sciences, Tehran and Mazandaran and described the purpose of the research and obtained the informed consent from the research samples, first took a history from the patients and if they had symptoms of candida vaginitis (itching, discharge, dyspareunia, or burning when urination) they were included in the study based on a preliminary questionnaire. 


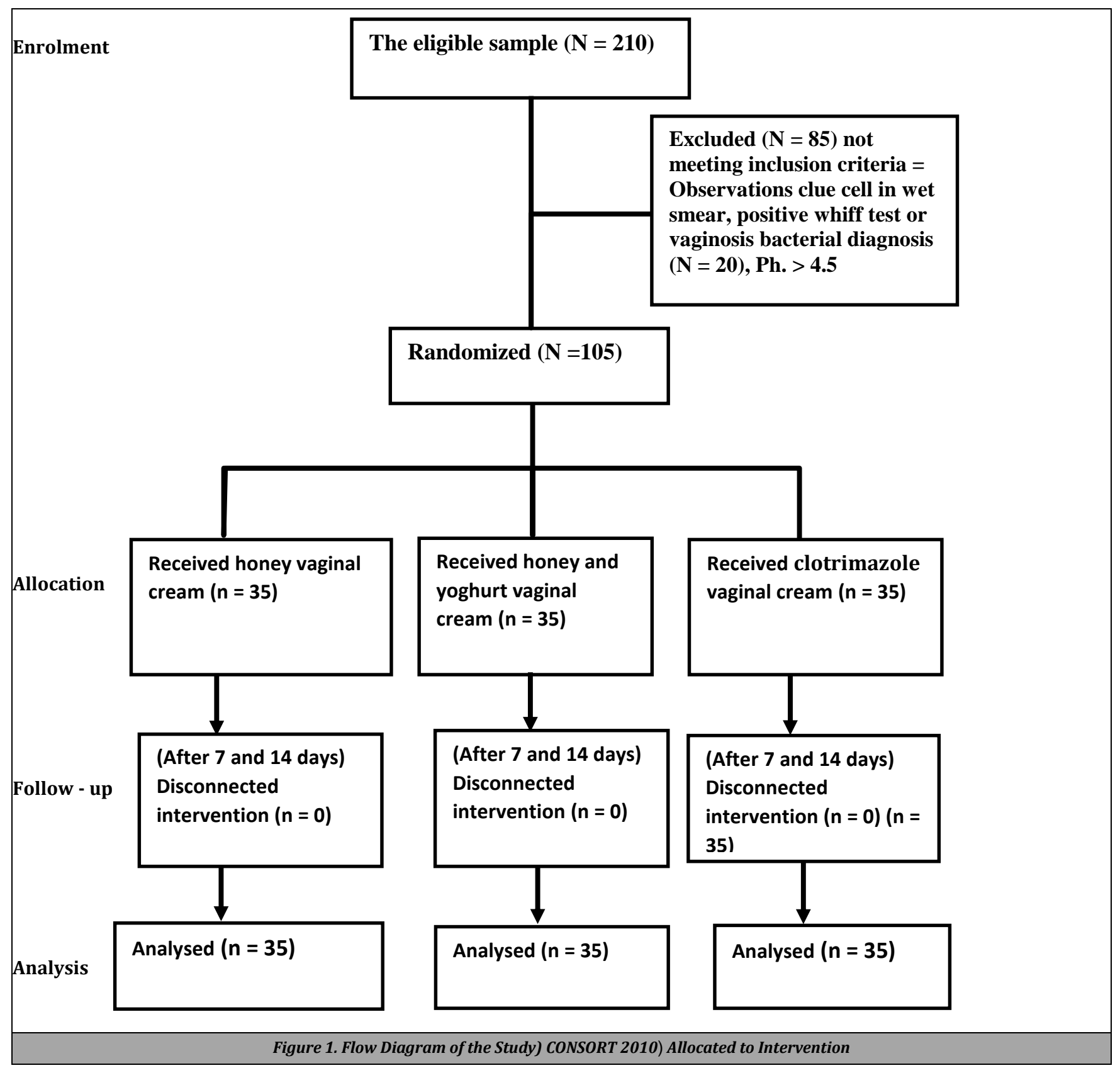

After fully explaining the research to the patients, the subject was placed in lithotomy position and, a sterile speculum was inserted into the vagina by the midwife without being impregnated with a substance, and first the cervix and vagina were observed for any abnormal findings and the observations were recorded in the checklist.

Then, using two sterile cotton swabs, a sample of secretions from the upper and lateral part of the vaginal wall was prepared and evaluated microscopically to observe mycelium and blast; $\mathrm{pH}$ above 4.5 measured by $\mathrm{pH}$ meter paper, mixed infection was detected and excluded from the study.

In case of positive culture in chromium agar culture medium, the diagnosis was definitive, and the sample was included in the study. PH was measured by $\mathrm{pH}$ meter paper.

The following creams were include, honey vaginal cream (water-insoluble solids: $0.4 \%$ and moisture: $18 \%$ ), yogurt and honey (water-insoluble solids: $0.4 \%$, moisture: $18 \%$ low-fat yogurt: $3.2 \%$, fat: $3.7 \%$ ) and dry matter content \& clotrimazole $1 \%$ were prepared by Professor of Pharmacognosy and people present in Armaghan Teb Company of Tehran who were completely unaware of the present study and the nature of the creams prepared were in a completely similar way in terms of shape, weight and size in matte tube and in the boxes. Some were named by code A - B $\mathrm{C}$. Then they were provided to the researcher for research.

From 210 women referred, finally 105 women with clinical signs of candidiasis and positive culture were included in the present study. They were then randomly divided into three groups of 35 people. The random allocation of patients was as follows; before the start of the study, 105 cards with the A - B - $\mathrm{C}$ code were prepared in equal numbers from each $(\mathrm{N}=35)$ and one of these codes was assigned to each patient. The patients were then randomly assigned to one of the three 
groups of "yogurt and honey", "honey" (intervention groups) and "clotrimazole" (control group), and they were asked to use an applicator ( $5 \mathrm{~g}$ ) inside the vagina each night for 7 nights.

Samples were asked to refer to clinic 7 and 14 days after completion of treatment with a coded card. Also, through phone calls, the time to visit was reminded to patients again, and were examined by a midwife present at the clinic and the result of the evaluation was recorded in observation checklist. The samples were evaluated microscopically.

For final confirmation of the presence or absence of fungal infection, subculture of samples was prepared then the therapeutic effect of the creams on the symptoms of the disease was evaluated. Patients, researchers and analysts were unaware of the nature of the creams due to their uniformity in shape, size and weight until the end of the intervention due to the coding of the creams. After the intervention and follow-up on the fourteenth day, the analysis was performed by Professor Amar. Finally, after presenting the results of the analysis, the codes were communicated by Professor of Pharmacognosy to the professor of statistics, researcher and participating samples. Post treatment symptoms of candida vulvovaginitis at 0,7 and 14 days were considered as outcomes of the study.

\section{Statistical Methods and Sample Size}

The sample size was determined with first type error of $5 \%$ and test power of ( $80 \%)$ and with prevalence of $\mathrm{P}_{1}=0.56$ and $\mathrm{P}_{2}=0.86$ from previous studies, at least 35 subjects in each group. The post-treatment outcomes were examined in threetime intervals (baseline, 7 and 14 days). ${ }^{30,31}$ The numbers were reported as percentage frequency with \pm mean standard deviation. Data was analysed using chi-square test and Fisher's exact test (to compare traits qualitatively used between the three groups), McNemar's test (for intragroup comparisons) and analysis of variance (ANOVA), to compare the mean of variables such as age, number of pregnancies and number of deliveries between the three groups for the independent variable and descriptive. $\mathrm{P}<0.05$ was considered as a significant level. Likewise, the effect size measurement was calculated by Cramer's V. Statistical Package for the Social Sciences (SPSS) statistical software (v. 21) has been used for analyses in this study.

Data collection tools in this study included information form for demographic variables, checklist for evaluation of patient's complaints and clinical observations (recording results of the first, second and third referrals including patients' complaints (5 questions) with choices (has / has not).

Microscope made by Olympus corporation Tokyo-Japan (model: cx31, Sn-5mo9248), pH-meter paper made in China (Q / CHSC1544-1999), CHROMagar culture plates, France, Paris brand and simple lamellae with glass tubes $(0.16 * 160)$ were utilised in clinical observation to record microscopic assessment results, culture outcome with negative-positive responses were same as in study that was carried out by Darvishi et al. (2015) ${ }^{32}$

\section{RESULTS}

Three groups in this study were similar in terms of demographic factors. The average age was $(7.5 \pm 32.51)$ in yogurt and honey group, $(7.5 \pm 32.51)$ in honey group and $(7.6$ \pm 33.89 ) in clotrimazole group. Similarly, the means numbers of pregnancy were $(1.29 \pm 1.83)$ in yogurt and honey group, $(1.23 \pm 0.77)$ in honey group and $(1.9 \pm 1.40)$ in clotrimazole group. The number of childbirths was $(1.33 \pm 1.57)$ in yogurt and honey group, $(1.9 \pm 1.54)$ in honey group and $(1.9 \pm 1.23)$ in clotrimazole group where ANOVA test did not show any significant difference among three groups in terms of these variables. (Table 1)

Females took contraceptive pills in yogurt and honey group (34.3\%), honey group (25.7\%) and clotrimazole group (31.4\%) in which no significant difference was observed among three groups in terms of given variables based on chisquare test.

Itching was most common symptom before treatment in referent females in yogurt and honey group 30 (85.7\%), in honey group $32(91.4 \%)$ and in clotrimazole group 34 (97.1 $\%)$ where no significant difference was seen between three groups based on Fisher's exact text. At the next step, vaginal secretions were common among three groups so that vaginal secretion was seen in yogurt and honey group 26 (74.3\%), honey group 26 (74.3\%) and clotrimazole group 29 (82.9\%) and all pre-treatment symptoms did not show significant difference in three groups using chi-square test. (Table 2)

\begin{tabular}{|c|c|c|c|c|}
\hline Variable & Clotrimazole & Honey & $\begin{array}{l}\text { Yoghurt and } \\
\text { Honey }\end{array}$ & P Value \\
\hline Average age & $33.89+7.6$ & $32.51+7.5$ & $32.51+7.5$ & \\
\hline \multicolumn{5}{|c|}{ Contraception } \\
\hline Have not & $7(20)$ & $7(20)$ & $0(0)$ & $P=0.43$ \\
\hline Condom & $9(25.75)$ & $8(22.9)$ & $10(28.6)$ & \\
\hline withdrawal & $5(14.3)$ & $7(20)$ & $10(28.6)$ & \\
\hline Pill & $11(31.4)$ & $9(25.7)$ & $12(34.3)$ & \\
\hline $\begin{array}{l}\text { The average } \\
\text { number of } \\
\text { pregnancies }\end{array}$ & $1.40+1.19$ & $0.77+1.23$ & $1.83+1.29$ & $P=0.29$ \\
\hline $\begin{array}{c}\text { The average } \\
\text { number of } \\
\text { deliveries }\end{array}$ & $1.23+1.19$ & $1.57+1.33$ & $1.54+1,19$ & $P=0.44$ \\
\hline \multicolumn{5}{|c|}{$\begin{array}{l}\text { Table 1. Characteristics of Women in Terms of } \\
\text { Intervention and Treatment Groups' Variables }\end{array}$} \\
\hline
\end{tabular}

The symptoms of disease were present among three groups at baseline, 7 and 14 days after intervention as shown in Tables 2 and 3. No treatment for itching was reported after 7 days in yogurt and honey group (5.7\%), honey group (8.6 $\%)$ and clotrimazole group (28.6\%) and the yogurt and honey group and honey group enjoyed effect size (0.291) compared to clotrimazole group. While this non-improvement in terms of abnormal vaginal secretions were in yogurt and honey group (5.7\%), honey group (5.7\%) and clotrimazole group $(22.9 \%)$ and two intervention groups enjoyed effect size (0.254) versus control group. Similarly, nontreatment of burning during urination and stimulation was implied in yogurt and honey group (5.7\%), honey vaginal cream group (8.6\%) and clotrimazole group (25.7\%) and effect size was 0.26 after 7 days of treatment. 


\begin{tabular}{|c|c|c|c|c|c|c|c|c|c|c|c|c|c|c|c|c|c|c|c|c|c|c|c|c|}
\hline \multirow{3}{*}{ Symptoms } & \multicolumn{8}{|c|}{ Before } & \multicolumn{8}{|c|}{ Seven Days } & \multicolumn{8}{|c|}{ Fourteen Days } \\
\hline & \multicolumn{2}{|c|}{$\begin{array}{c}\text { Clotrima } \\
\text { zole }\end{array}$} & \multicolumn{2}{|c|}{$\begin{array}{l}\text { Yogurt \& } \\
\text { Honey }\end{array}$} & \multicolumn{2}{|c|}{ Honey } & \multirow{2}{*}{$\begin{array}{c}\text { p- } \\
\text { value }\end{array}$} & \multirow{2}{*}{$\begin{array}{c}\text { Effect } \\
\text { Size }\end{array}$} & \multicolumn{2}{|c|}{$\begin{array}{c}\text { Clotrim } \\
\text { azole }\end{array}$} & \multicolumn{2}{|c|}{$\begin{array}{c}\text { Yoghurt \& } \\
\text { Honey }\end{array}$} & \multicolumn{2}{|c|}{ Honey } & \multirow{2}{*}{$\begin{array}{c}\text { p- } \\
\text { value }\end{array}$} & \multirow{2}{*}{$\begin{array}{c}\text { Effect } \\
\text { Size }\end{array}$} & \multicolumn{2}{|c|}{$\begin{array}{c}\text { Clotrimaz } \\
\text { ole }\end{array}$} & \multicolumn{2}{|c|}{$\begin{array}{c}\text { Yogurt \& } \\
\text { Honey }\end{array}$} & \multicolumn{2}{|c|}{ Honey } & \multirow{2}{*}{$\begin{array}{c}\text { p- } \\
\text { value }\end{array}$} & \multirow{2}{*}{$\begin{array}{c}\text { Effect } \\
\text { Size }\end{array}$} \\
\hline & $\mathbf{n}$ & $\%$ & $\mathbf{n}$ & $\%$ & $\mathbf{N}$ & $\%$ & & & $\mathbf{n}$ & $\%$ & n & $\%$ & $\mathbf{n}$ & $\%$ & & & $\mathbf{n}$ & $\%$ & $\mathbf{n}$ & $\%$ & $\mathbf{n}$ & $\%$ & & \\
\hline Leucorrhoea & 29 & 82.9 & 26 & 74.3 & 26 & 74.3 & 0.615 & 0.096 & 8 & 22.9 & 2 & 5.7 & 2 & 5.7 & 0.051 & 0.254 & 8 & 22.9 & 1 & 2.9 & 1 & 2.9 & 0.006 & 0.321 \\
\hline Itch & 32 & 91.4 & 30 & 85.7 & 33 & 94.3 & 0.461 & 0.121 & 10 & 28.6 & 2 & 5.7 & 3 & 8.6 & 0.017 & 0.291 & 9 & 25.7 & 1 & 2.9 & 5 & 14 & 0.023 & 0.267 \\
\hline Irritation & 24 & 68.6 & 27 & 71.1 & 25 & 71.4 & 0.716 & 0.08 & 9 & 25.7 & 2 & 5.7 & 3 & 8.6 & 0.038 & 0.26 & 8 & 22.9 & 1 & 2.9 & 2 & 5.7 & 0.018 & 0.288 \\
\hline Dysuria & 20 & 57.1 & 18 & 51.4 & 21 & 60.0 & 0.763 & 0.072 & 4 & 11.7 & 1 & 2.9 & 1 & 2.9 & 0.361 & 0.174 & 3 & 8.6 & 0 & 0 & 1 & 2.9 & 0.32 & 0.186 \\
\hline Dyspareunia & 22 & 62.9 & 25 & 71.4 & 21 & 60.0 & 0.581 & 0.102 & 9 & 25.7 & 6 & 17.1 & 6 & 17.1 & 0.711 & 0.101 & 8 & 22.9 & 4 & 11.4 & 4.0 & 11 & 0.3 & 0.15 \\
\hline & & & & & & Dis & ibuti & of $A l$ & & $a$ & & tive & 8 & 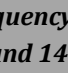 & $f P$ & $\begin{array}{l}\text { ch } \\
r \text { th }\end{array}$ & 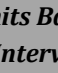 & H & & & & & & \\
\hline
\end{tabular}

\begin{tabular}{|c|c|c|c|c|c|c|}
\hline & \multicolumn{3}{|c|}{7 Days After } & \multicolumn{3}{|c|}{14 Days After } \\
\hline & $\begin{array}{l}\text { Clotrima- } \\
\text { zole }\end{array}$ & $\begin{array}{l}\text { Yogurt } \\
\text { Honey }\end{array}$ & Honey P & $\begin{array}{l}\text { Clotrim- } \\
\text { azole }\end{array}$ & $\begin{array}{l}\text { Yogurt } \\
\text { Honey }\end{array}$ & Honey $\mathbf{P}$ \\
\hline $\begin{array}{l}\text { Microscopic } \\
\text { evaluation }\end{array}$ & 32 (91.4) & $28(80)$ & $\begin{array}{c}27 \\
(77.1)\end{array}$ & $32(91.4)$ & $29(82.9)$ & $\begin{array}{cc}29 & 0.49 \\
(82.9) & 0.49\end{array}$ \\
\hline Culture & $28(80)$ & $24(68.6)$ & $\left.\begin{array}{c}22 \\
(62.9)\end{array}\right) .27$ & $30(85.7)$ & $25(71,4)$ & $\begin{array}{cc}24 \\
(68.4)\end{array}$ \\
\hline & $\begin{array}{r}\text { Table } \\
\text { icroscopi } \\
\text { Culture }\end{array}$ & $\begin{array}{l}\text { 3. Dist } \\
\text { Evaluo } \\
\text { Results, }\end{array}$ & $\begin{array}{l}\text { ution of } S a \\
\text { n Result of } \\
\text { eatment PI }\end{array}$ & $\begin{array}{l}\text { mple Ba } \\
\text { f Wet Sli } \\
\text { hases an }\end{array}$ & $\begin{array}{l}\text { don } \\
\text { and Flui } \\
\text { Groups }\end{array}$ & \\
\hline
\end{tabular}

The adjusted Fisher's exact test showed significant statistical difference between three groups in terms of above said symptoms (vaginal secretion, itching and burning sensation during urination) in yogurt and honey group and honey vaginal cream group versus clotrimazole group. Also, using McNemar's statistical test, there was a significant difference in terms of improvement of the above symptom before and after treatment. Likewise, the subject enjoyed effect size that indicated improvement of conditions in patient. (Table 2)

Similarly, results of current study showed that negative nature of culture after treatment was in yogurt and honey group (71.4\%), honey group (68.6\%) and clotrimazole group $(85.7 \%)$ where it did not indicate any significant statistical difference among three groups by chi-square test.

On the other hand, significant difference was observed in negative trend of culture after treatment in all three groups versus baseline using McNemar's test. (Table 3).

\section{DISCUSSION}

The present research was a clinical trial study on three groups that have been dealt with effect of comparison of honey vaginal cream, yogurt and honey mixture with clotrimazole in control group on symptoms of Candida vulvovaginitis among females. The findings from the study suggest that following use of honey vaginal cream alone for seven days and in combination with yogurt, symptoms of candida vulvovaginitis remarkably reduced. The rate of improvement in terms of itching, secretions and burning when urination was better in honey and yogurt group and honey group than in clotrimazole group. Similarly, the effect size was noticeably better in honey and yogurt group and honey group than in clotrimazole group.

The results of current study were consistent with the findings from study of Reda et al. concerning treatment of itching and burning when urination, in group that received honey and self- care versus self-care group alone. Also, in study done by Fazel et al. only honey and in combination with clotrimazole improved symptoms of candida vulvovaginitis.$^{33}$ The reason for difference in improvement percentage from current study may be due to difference in measurement tools and geographic zone of studied group.

Whereas in current study, honey vaginal cream alone or in combination of yogurt improved itching and secretions than clotrimazole but in study done by Rasooli et al., medicinal effects of cinnamon vaginal cream and honey on itching and secretions were similar to clotrimazole thus such a difference could be due to combination of cinnamon with honey while in current study honey was mixed with yogurt that increased synergistic effect of honey. ${ }^{34}$ Dyspareunia and dysuria were reduced in all three groups, such improvement can be due to the presence of honey because of existing flavonoids in honey because in study done by Ibrahimi et al. 35 improvement in dyspareunia was same in both groups of garlic and fluconazole. However, in a study conducted by Darvishi et al. $(2015)^{32}$, noticeable improvement was seen in itching and amount of vaginal secretion in yogurt and honey group versus clotrimazole group. These consistent findings with the current study can suggest effectiveness of yogurt and honey mixture on growth inhibition of colonization in all candida varieties and they are consistent with the results of findings from study of Irish et al. ${ }^{36}$ This consistency may be due to antimicrobial effects of honey because of its high osmolality.

The present research showed honey and yogurt mixture caused synergistic effect of honey against candida variety and it is consistent with findings from study of Bukra et al. synergistic impact of honey and starch against Candida albicans. ${ }^{37}$ However, the finding of current research is not consistent with study of Pirota et al. It can be due to the fact that participants attended in study were after taking antibiotics in study of Pirota et al. ${ }^{38}$ while non-use of antibiotics was one of the sampling inclusions in the present research. Thus, results of current finding indicate effectiveness of yogurt and honey and honey on negative culture in samples within 7 days after intervention. Likewise, it enjoyed RR suitable rate so that mechanism of antimicrobial activity of honey intervenes in effect of some phenomena including low $\mathrm{pH}$, osmolality of honey and production of hydrogen peroxide and other factors. Thus, using honey in current study inhibited growth in all varieties of candida in culture medium and this finding is consistent with study of Khosravi et al.

Whereas one of the exclusion criteria was taking antibiotic in sampling at this study thus result of present study is not consistent with study of Pirota et al. ${ }^{38}$ concerning role of oral or vaginal varieties of lactobacillus in prevention from candida vulvovaginitis after taking antibiotics. 


\section{CONCLUSIONS}

Administration of honey in combination with yogurt may exert favourable impact on treatment of candida vulvovaginitis in the current study and causes reduction and improvement of symptoms of candida vulvovaginitis. Similarly, it is costeffective and has no side-effects of synthetic drugs. Therefore, taking them in combination with each other can be useful in formulations of topical drugs to treat vaginal candidiasis.

The triple blind nature, random attribution of samples in the three groups and inclusion of control group are the strengths of this study. Introduction of a natural product without specific side-effect and ease of use is another strength of this study. Small sample size is a limitation of this study.

Data sharing statement provided by the authors is available with the full text of this article at jemds.com.

This article is an extract of a MS thesis funded by Tehran University of Medical Science.

Disclosure forms provided by the authors are available with the full text of this article at jemds.com.

The authors express their gratitude to the respected research deputy of Tehran and Mazandaran Universities of Medical Sciences for cooperation and assistance and all colleagues who assisted us in conducting this project.

This study was registered in the Iranian Registry of Clinical Trials (http://www.irct.ir) with the registration code No 14201401052248

\section{REFERENCES}

[1] Ezeigbo OR, Anolue FC, Nnadozie IA. Vaginal candidiasis infection among pregnant women in Aba, Abia state, Nigeria. Journal of Advances in Medicine and Medical Research 2015;9(3):1-6.

[2] Buggio L, Somigliana E, Borghi A, et al. Probiotics and vaginal microecology: fact or fancy? BMC Women's Health 2019;19:25.

[3] Aguirre-Quiñonero A, de Castillo-Sedano IS, Calvo-Muro $\mathrm{F}$, et al. Accuracy of the BD MAX ${ }^{\mathrm{TM}}$ vaginal panel in the diagnosis of infectious vaginitis. Eur J Clin Microbiol Infect Dis 2019;38(5):877-82.

[4] Ahangari F, Farshbaf-Khalili A, Javadzadeh Y, et al. Comparing the effectiveness of Salvia officinalis, clotrimazole and their combination on vulvovaginal candidiasis: a randomized, controlled clinical trial. J Obstet Gynaecol Res 2019;45(4):897-907.

[5] Swidsinski A, Guschin A, Tang Q, et al. Vulvovaginal candidiasis: histologic lesions are primarily polymicrobial and invasive and do not contain biofilms. Am J Obstet Gynecol 2019;220(1):91.e1-91.e8.

[6] Horvath LL, Hospenthal DR, Murray CK, et al. Direct isolation of Candida spp. from blood cultures on the chromogenic medium CHROMagar Candida. J Clin Microbiol 2003;41(6):2629-32.

[7] Willems HME, Ahmed SS, Liu J, et al. Vulvovaginal candidiasis: a current understanding and burning questions. J Fungi (Basel) 2020;6(1):27.

[8] Hermanns R, Cremers NAJ, Leeming JP, et al. Sweet relief: determining the antimicrobial activity of medical grade honey against vaginal isolates of candida albicans. J Fungi (Basel) 2019;5(3):85.
[9] Tehrani FR, Farahmand M, Abedini M, et al. Prevalence of vaginitis in Iranian women--symptoms and clinical association. Medical Science Journal of Islamic Azad University Tehran Medical Branch 2012;22(1):62-8.

[10]Yan L, Wang XD, Seyedmousavi S, et al. Antifungal susceptibility profile of Candida albicans isolated from vulvovaginal candidiasis in Xinjiang province of China. Mycopathologia 2019;184(3):413-22.

[11] Lopez JEM. Candidiasis (vulvovaginal). BMJ Clin Evid 2015;2015:0815.

[12] Emeribe AU, Nasir IA, Onyia J, et al. Prevalence of vulvovaginal candidiasis among nonpregnant women attending a tertiary health care facility in Abuja, Nigeria. Research and Reports in Tropical Medicine 2015;6:37-42.

[13]Akortha EE, Nwaugo VO, Chikwe NO. Antifungal resistance among Candida species from patients with genitourinary tract infection isolated in Benin City, Edo state, Nigeria. African Journal of Microbiology Research 2009;3(11):694-99.

[14] Asadzadeh M, Ahmad S, Al-Sweih N, et al. Rapid molecular differentiation and genotypic heterogeneity among Candida parapsilosis and Candida orthopsilosis strains isolated from clinical specimens in Kuwait. J Med Microbiol 2009;58(Pt 6):745-52.

[15] Farhan MA, Moharram AM, Salah T, et al. Types of yeasts that cause vulvovaginal candidiasis in chronic users of corticosteroids. Med Mycol 2019;57(6):681-7.

[16] Warren T. Is it a yeast infection? 2010. https:// www.webmd.com/women/features/is-it-yeast-infection

[17] Burkman RT. Berek \& Novak's gynecology. JAMA 2012;308:516-7.

[18] Azike CA, Nwokah EG, Abbey SD. Molecular characterization and phylogeny of Candida species isolated from high vaginal swab samples among patients presenting with vulvovaginal candidiasis in Port Harcourt, Nigeria. European Journal of Biomedical and Pharmaceutical Sciences 2018;5(7):83-9.

[19] Watson C, Calabretto H. Comprehensive review of conventional and non-conventional methods of management of recurrent vulvovaginal candidiasis. Aust N Z J Obstet Gynaecol 2007;47(4):262-72.

[20] Sobel JD, Wiesenfeld HC, Martens M, et al. Maintenance fluconazole therapy for recurrent vulvovaginal candidiasis. N Engl J Med 2004;351(9):876-83.

[21] Jones R. Honey and healing through the ages. Journal of ApiProduct and ApiMedical Science 2009;1(1):2-5.

[22] Eteraf-Oskouei T, Najafi M. Traditional and modern uses of natural honey in human diseases: a review. Iran J Basic Med Sci 2013;16(6):731-42.

[23] Sobel J, Zervos M, Reed B, et al. Fluconazole susceptibility of vaginal isolates obtained from women with complicated Candida vaginitis: clinical implications. Antimicrob Agents Chemother 2003;47(1):34-8.

[24] Alzubier AA, Okechukwu PN. Investigation of antiinflammatory, antipyretic and analgesic effect of Yemeni Sidr Honey. World Academy of Science Engineering Technology International Journal of Nutrition and Food Engneering 2011;5(8):41-6.

[25] Vallianou NG, Gounari P, Skourtis A, et al. Honey and its anti - inflammatory, anti - bacterial and anti - oxidant properties. Gen Med (Los Angel) 2014;2(2):1-5. 
[26] Ehrström S, Daroczy K, Rylander E, et al. Lactic acid bacteria colonization and clinical outcome after probiotic supplementation in conventionally treated bacterial vaginosis and vulvovaginal candidiasis. Microbes Infect 2010;12(10):691-9.

[27] Al-Waili N, Akmal M, Al-Waili F, et al. The antimicrobial potential of honey from United Arab Emirates on some microbial isolates. Med Sci Monit 2005;11(12):BR433-8.

[28] Aboushady RMN, Eswi A, Mostafa FAM. Sider honey Vs. fluconazole and the cure rate of vulvovaginal candidiasis. IOSR Journal of Nursing and Health Science (IOSR - JNHS) 2015; Vol. 4.

[29] Shalev E, Battino S, Weiner E, et al. Ingestion of yogurt containing lactobacillus acidophilus compared with pasteurized yogurt as prophylaxis for recurrent candidal vaginitis and bacterial vaginosis. Arch Fam Med 1996;5(10):593-6.

[30]Panidis D, Kourtis A, Farmakiotis D, et al. Serum adiponectin levels in women with polycystic ovary syndrome. Hum Reprod 2003;18(9):1790-6.

[31] Bonyadpour B, Akbarzdeh M, Pakshir K, et al. In vitro susceptibility of fluconazole, clotrimazole and toucrium polium smoke product on candida isolates of vaginal candidiasis. Armaghane Danesh 2009;14(2):87-96.

[32]Darvishi M, Jahdi F, Hamzegardeshi Z, et al. The comparison of vaginal cream of mixing yogurt, honey and clotrimazole on symptoms of vaginal candidiasis. Glob J Health Sci 2015;7(6):108-16.

[33] Fazel N, Hashemian M, Ramezani M, et al. Comparison of honey with clotrimazole alone and mixed on candidial vaginitis. Iranina Journal of Obstetrics Gynecology and Infertility 2011;14(8):48-54.

[34] Rasooli T, Nahidi F, Mojab F, et al. Effect of honey cinnamon vaginal cream and clotrimazole vaginal cream on improvement of candida vaginitis symptoms in women: Randomized clinical trial. The Iranian Journal of Obstetrics, Gynecology and Infertility 2019;22(3):59-67.

[35] Ebrahimian A, Rahmani R, Sharifi N. Evaluation of the effect of honey vaginal gel in the treatment of candidal vaginitis. presented at the the first student research congress of Khorasan University of Medical Sciences 2019.

[36] Irish J, Carter DA, Shokohi T, et al. Honey has an antifungal effect against Candida species. Med Mycol 2006;44(3):289-91.

[37] Boukraâ L, Bouchegrane S. Additive action of honey and starch against Candida albicans and Aspergillus Niger. Rev Iberoam Micol 2007;24(4):309-11.

[38] Pirotta MV, Gunn JM, Chondros P. Not thrush again! Women's experience of post-antibiotic vulvovaginitis. Med J Aust 2003;179(1):43-6. 